\title{
Study on the Potential Use of Modified Tapioca Starch Sludge Waste for Volatile Fatty Acid Generation
}

\author{
Piyavadee Srivichai ${ }^{1, *}$, Chumaporn Rodsrida ${ }^{2}$, \\ Nakit Chansamut $^{3}$ and Wirinya Mueangchang ${ }^{4}$
}

${ }^{1}$ Program in Environmental Health, School of Public Health, University of Phayao, Phayao 56000, Thailand

${ }^{2}$ Program in Occupational Health and Safety, School of Public Health, University of Phayao, Phayao 56000, Thailand

${ }^{3}$ Department of Pathology, School of Medicine, University of Phayao, Phayao 56000, Thailand

${ }^{4}$ Program in Applied Thai Traditional Medicine, School of Public Health, University of Phayao, Phayao 56000, Thailand

("Corresponding author’s e-mail: u4108047@hotmail.com)

Received: 15 October 2020, Revised: 6 June 2021, Accepted: 15 June 2021

\begin{abstract}
Starch sludge (SS) is a bulky main waste from modified tapioca starch production, a high potential substrate for alternative volatile fatty acids (VFA) production. Because it has relatively high organic content in SS is easy and fast to convert into VFA. However, there are limitations when fed overloading rate to anaerobic digestion (AD) system affecting the VFA production yield and system performance. This research aims to study the effect of initial feeding concentrations of SS between 0.5 and $2.5 \%$ total volatile solids (TVS) on the VFA production efficiency by applying a batch continuously stirred tank reactor (CSTR) for digestion. The maximum VFA yield was $115 \mathrm{mg}$ VFA/g TVS at a feeding rate of 2.0 $\%$ TVS of SS after 4 days of digestion. The digestion system could run under proper system performance and stability by showing higher $\mathrm{pH}$. Besides, acetic acid was the predominant VFA intermediate indicating great effective digestion. Finally, the main bacteria in the inoculum were Arenimonas up to 33 $\%$ because it preferred to grow on glucose. And inoculum obtained from the beverage plant's wastewater treatment system. These were so useful to select the inoculum for organic starch digestion.
\end{abstract}

Keywords: Starch sludge, Volatile fatty acid, Modified tapioca starch, Anaerobic digestion, Arenimonas

\section{Introduction}

VFA are valuable intermediates in the AD process. Many VFA types, such as acetic acid, propionic acid, butyric acid, etc., each type of VFA is widely used in the food, pharmaceutical, and chemical industries [1,2]. They can be applied as the building blocks for chemical and biofuel, offering a vital economic advantage [3]. Recently, World VFA demand is projected to be around 18,500 million tons in 2020 , representing $97 \%$ of acetic acid, $2.5 \%$ of propionic acid and $0.5 \%$ of butyric acid. Moreover, there has been a continuous increase in demand every year [4].

More recent works show that both starch and glucose are suitable for VFA production under appropriate conditions [3]. For instance, Strazzera et al. [2] found that food waste was fed with an organic loading rate of about $10 \mathrm{~kg}$ of $\mathrm{TVS} / \mathrm{m}^{3} \mathrm{~d}$ operating at thermophilic temperatures. Obtaining the optimal VFA yield was $0.27 \mathrm{~g} \mathrm{VFA} / \mathrm{g}$ total solid (TS) at an operating $\mathrm{pH}$ of 7 . Also, canteen food waste [5] and lignocellulosic sugar [6] have a high potential in acetic acid production. Typically, VFA production from oil generates several hazardous wastes such as heavy metals and organic solvents, including greenhouse gasses [3]. Thus, the way to seek other substitutes for VFA production is an appropriate choice.

In Thailand, approximately 1.01 million tons of SS annually in the tapioca starch industries were discarded as waste [7]. Typically, it was mostly sold for animal food production at a relatively low price of 73 - 97 dollars per ton [8]. Moreover, it is not sustainable to treat efficiently because of its nonenvironmentally friendly resulted in the strong bad smell, the spread of insects and the important aspect of leachate in the rainy season. On the other hand, starch generally contains 20 to $25 \%$ amylose and 75 to 
$80 \%$ amylopectin [9] is interesting to produce potentially VFA using AD process. Also, solving the SS waste management problem because it operates as closed systems [10].

The main aim of this work was to study the VFA production efficiencies from SS varying base on the initial concentration. Also, we assessed bacterial diversity and distribution in the inoculum to understand the relationship between this AD condition and the bacterial community. These found out the optimum possible choice to increase the value of SS waste for VFA production.

\section{Materials and methods}

\section{Substrate and feedstock preparation}

$\mathrm{SS}$ is the substrate for this AD (Figure 1) that was collected from the dewatering filter press machine. It received sludge from the primary sedimentation pond of the tapioca starch wastewater treatment plant located in Rayong province of eastern Thailand. The inoculum utilized for seeding digestion came from the up-flow anaerobic sludge blanket reactor (UASB) system of the brewery plant in Nonthaburi province.

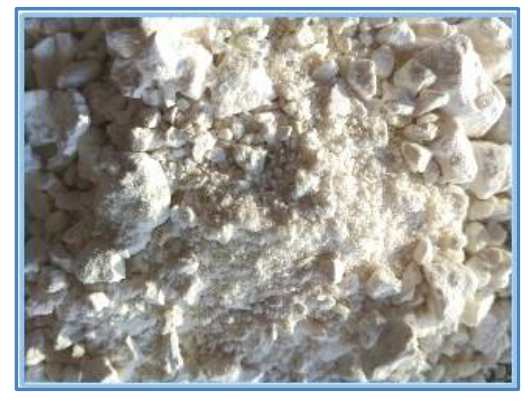

(A)

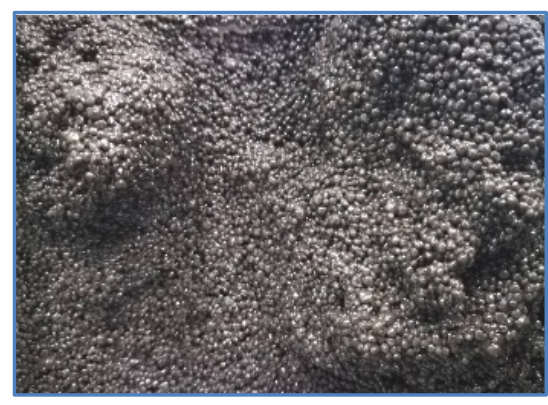

(B)

Figure 1 The features of (A) SS and (B) Inoculum.

Table 1 The characteristics of SS and inoculum.

\begin{tabular}{ccc}
\hline \multirow{2}{*}{ Parameter } & \multicolumn{2}{c}{ Substrate } \\
\cline { 2 - 3 } SS & Inoculum \\
\hline $\mathrm{pH}$ & 4.53 & - \\
\%TVS & 258 & 8.51 \\
\%TS & 31.78 & 6.73 \\
TVS/TS & 61 & 6.95 \\
\hline
\end{tabular}

The SS and inoculum were characterized in terms of $\mathrm{pH}$, carbon to nitrogen $(\mathrm{C} / \mathrm{N})$ ratio and TVS to TS (TVS/TS) ratio as shown in Table 1. The SS be acidic, which may be beneficial for VFA production. It could help to balance and maintain the optimal acid $\mathrm{pH}$ for digestion to produce VFA. There were suggestions of $\mathrm{pH}$ value as 4-6[11,12]. Including, SS had the high applicable organic content with TVS/TS ratio of 0.53 higher than the recommended value of 0.5 [13]. Significantly, a relatively high C/N ratio was a sign that it could be digested rapidly to VFA causing the sharp reduction in $\mathrm{pH}$ [14]. Therefore, its usage must concern about $\mathrm{pH}$ affecting digestive stability. The feedstock was prepared as a solution mixture of SS and inoculum by diluting with distilled water. The filled SS and inoculum determinants can be calculated using the following Eq. (1). Each batch feedstock was prepared of $5 \mathrm{~L}$. The concentrations of inoculum were fixed at $2.5 \%$ TVS for every digestion.

$\mathrm{TVS}_{1} \mathrm{~W}_{1}=\mathrm{TVS}_{2} \mathrm{~W}_{2}$

where $\quad \mathrm{TVS}_{1}=\mathrm{TVS}$ of the initial SS or inoculum (\%TVS);

$\mathrm{W}_{1}=$ Weight of SS or inoculum $(\mathrm{g})$;

$\mathrm{TVS}_{2}=$ TVS of prepared feedstock (\%TVS); and

$\mathrm{W}_{2}=$ Weight of prepared feedstock $(\mathrm{g})$. 
Figure 2 presents the presence of $\mathrm{C} / \mathrm{N}$ ratios and inoculum to substrate ratios (ISR) in feedstock varying with the SS concentrations between 0.5 and $2.5 \% \mathrm{TVS}$. Their values were compared to the range of recommended $\mathrm{C} / \mathrm{N}$ ratio of $20-30$ [15] and ISR of $0.3-1$ [16,17]. These cover the recommended ranges, which may contribute sufficiently to VFA production.

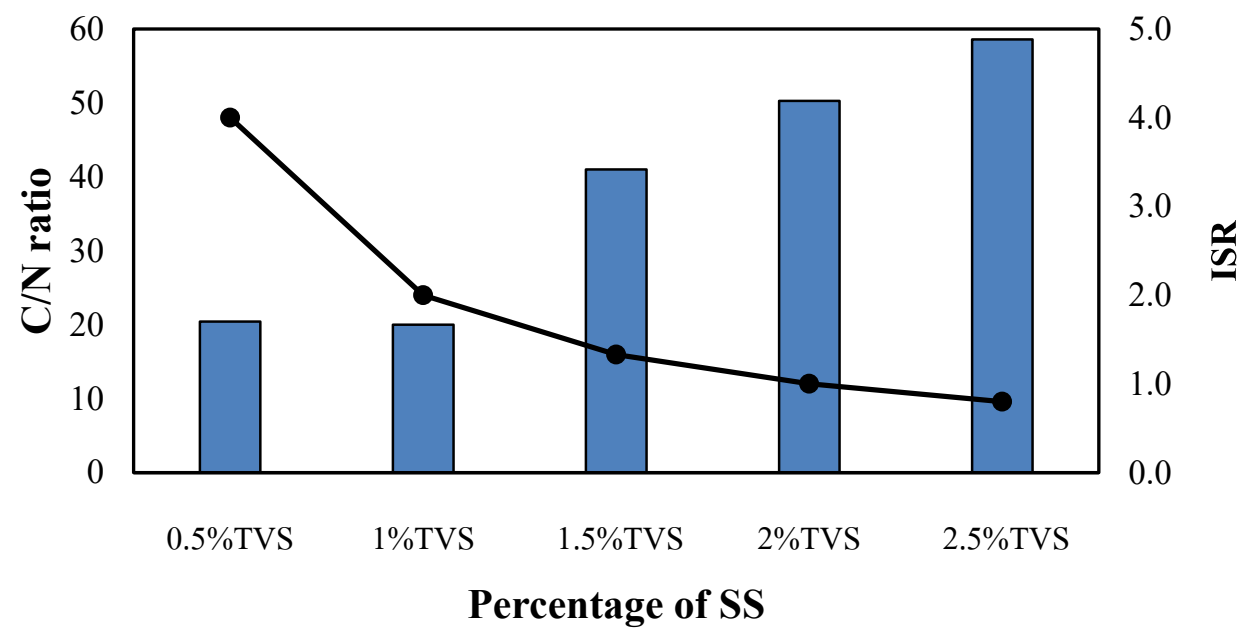

Figure 2 The $\mathrm{C} / \mathrm{N}$ and ISR ratios of feedstock at various concentrations.

\section{Setup and analytical methods}

Six L batch continuous stirred tank reactor (CSTR) was applied with a fermentation volume of $5 \mathrm{~L}$. The CSTR was operated at room temperature with the hydraulic retention time (HRT) for 10 days. It was mixed with a propeller at a rotating speed of $70 \mathrm{rpm}$ every $15 \mathrm{~min}$ an hour (Figure 3). After the stop stirring for $15 \mathrm{~min}$, the supernatant was kept analyzing the inner $\mathrm{pH}$, VFA and alkalinity (ALK). The analytical methods were made according to the American Public Health Association standard [18].

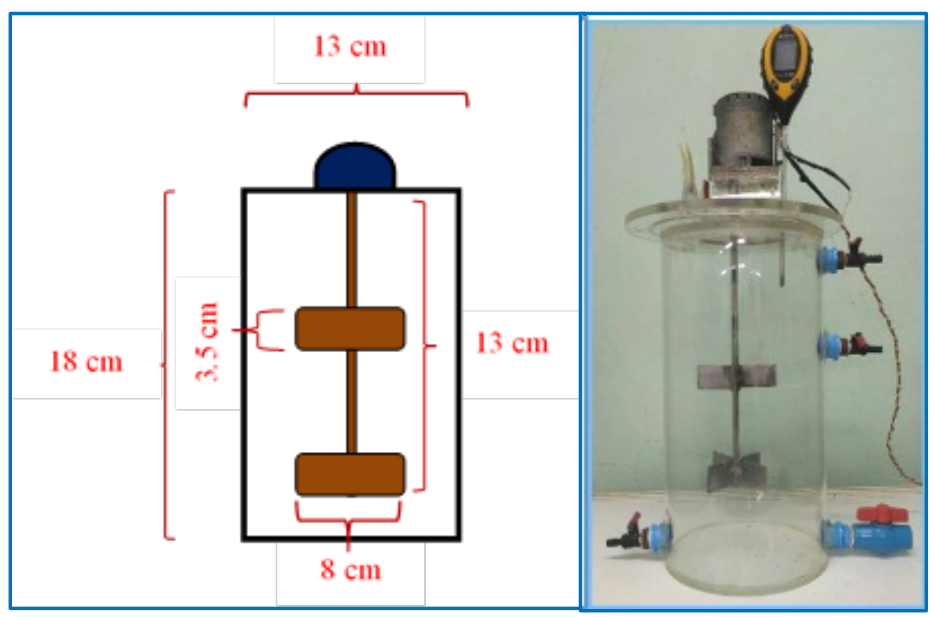

Figure 3 The CSTR reactor.

At the concentration achieved the optimum VFA yield and performance, the VFA composition was classified by gas chromatography (GC) method with flame ionization detection (FID) (Model Shimadzu GC-2014, capillary column: ULBON HR-20 (0.25 $\mu \mathrm{m}$ Film thickness, $0.25 \mathrm{~mm}$ Inner diameter, $25 \mathrm{~m}$ length), column temperature program $100{ }^{\circ} \mathrm{C}$, injection temperature $190{ }^{\circ} \mathrm{C}$ ). The helium was applied as a carrier gas at a flow rate of $59 \mathrm{~mL} / \mathrm{min}$. 


\section{Bacterial classification in the CSTR}

The application of 16S rRNA (ribosomal ribonucleic acids) gene sequences was to study bacterial taxonomy in the CSTR. The inoculum was collected and extracted using sodium dodecyl sulfate (SDS) and cetyltrimethylammonium bromide (CTAB) method. The specific primers (16S V4: 515F-806R, 18S V4: 528F-706R, 18S V9: 1380F-1510R) were amplified with the polymerase chain reaction (PCR) method. Samples with a bright main strip between 400 - 450 base pairs were selected for analysis. After that, the PCR sample was purified with Qiagen Gel Extraction Kit, Germany. The reference database (Gold database, http://drive5.com/uchime/uchime_download.html) was applied to identify the type of bacterial tag. The same operational taxonomy units (OTUs) were more similar than $97 \%$.

\section{Results and discussion}

\section{VFA concentrations and yields}

As presented in Figure 4, the digester was monitored immediately in the concentration of VFA. Besides, VFA yields were calculated per unit of TVS added. VFA concentrations were found to increase with the increase of feeding SS concentration. Significantly, their concentrations had sharply raised at the beginning $1^{\text {st }}$ day. Later, all the concentrations had not any increase showing consistency values. Both 2 and $2.5 \%$ TVS of SS were arranged on the same highest line. This refers to the system that produced the nearby concentration of VFA.

In considering VFA yield, the system had the highest yield of about $160 \mathrm{mg}$ VFA/g TVS when the initial loading rate was $0.5 \%$ TVS of SS. In comparison, the most loading rates between 0.5 and $2.0 \%$ TVS of SS achieved the VFA yield at around $98-115 \mathrm{mg}$ VFA/g TVS. Apparently, at the loading rate 2.5 $\%$ TVS of SS could be seen the more different from others. By the VFA, yields went down by approximately $45 \%$ from the highest value. Compared with other works, the maximum was $208 \mathrm{mg}$ VFA/g TVS production from microalgal biomass using CSTR under mesophilic conditions [19]. Several digestion scenarios obtained VFA yields of $175-243 \mathrm{mg}$ VFA/g TVS from sewage, adding different concentrations of wollastonite [20]. The VFA yield in this work was lower than the previous one. But it was rather near the VFA yield produced from household food waste that gets the highest yield of $104 \mathrm{mg}$ VFA/g TVS [2]. It illustrated that the SS fermentation is the possible suitable and effective choice to further develop for VFA production. Especially at the SS concentrations between 0.5 and $2 \%$ TVS when focusing on VFA yields.

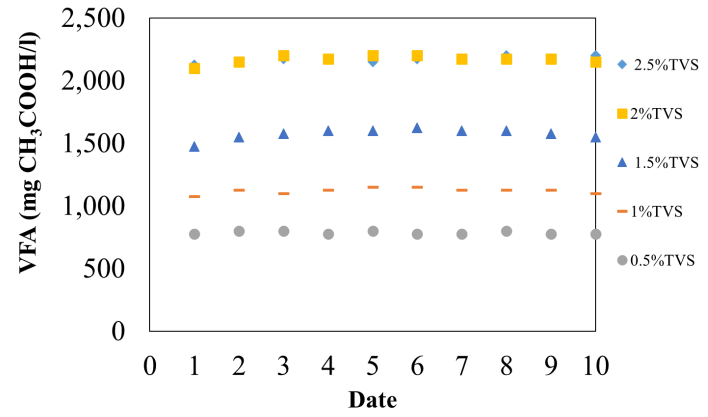

(A)

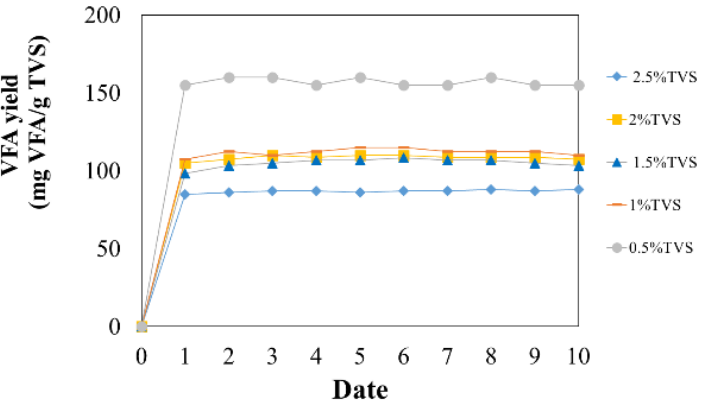

(B)

Figure 4 Represents VFA (A) concentrations and (B) VFA yields at various initial SS concentrations. 


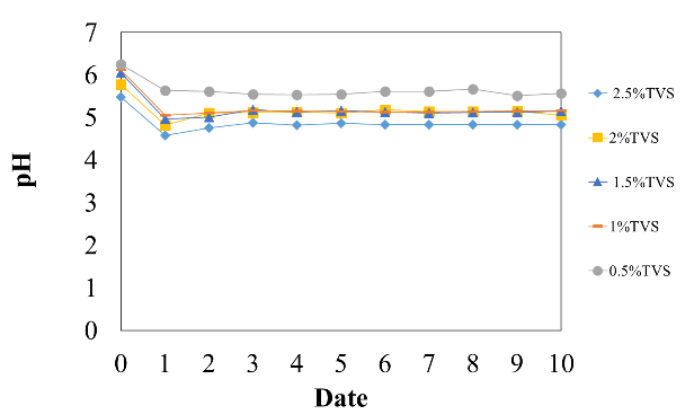

(A)

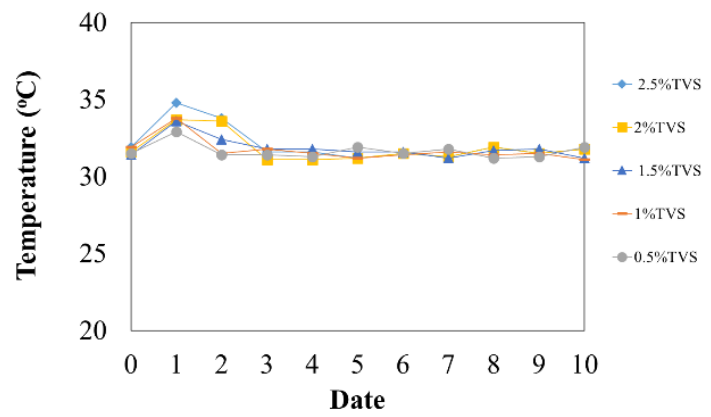

(B)

Figure 5 Represents (A) Inner pH values and (B) temperatures at various initial SS concentrations.

\section{The digestive condition}

The digester parameters such as $\mathrm{pH}$, temperature, and VFA/ALK were applied to monitor system performance and stability. Obviously, the substantial reduction of $\mathrm{pH}$ in the CSTR reactor occurred within the $1^{\text {st }}$ day of digestion (Figure 5(A)). Most concentrations of SS had acidic $\mathrm{pH}$ values close to 5 , except only at the concentration of $0.5 \%$ TVS of SS. There were few differences between the most concentrations. These were a little smaller than the recommended $\mathrm{pH}$ value between $5.5-6.5$ for system stability. Significantly, at $2.5 \%$ TVS of SS had a high risk of failure showing the lowest $\mathrm{pH}$ value. Therefore, the high concentration application of SS should be aware of this issue. Since the rapid digestion of starch causing the $\mathrm{pH}$ to drop immediately [1]. These corresponded roughly with the temperature values (Figure 5(B)). There was also an extreme increase in inner temperature on the $1^{\text {st }}$ day of digestion. The highest temperature was $34.8{ }^{\circ} \mathrm{C}$ at the concentration of $2.5 \%$ TVS of SS, while the other concentrations were higher than $33{ }^{\circ} \mathrm{C}$. Then, most of the concentrations declined to similar temperatures as the beginning of digestion. Only at the $2 \%$ TVS of SS kept the high static temperature on the $2^{\text {nd }}$ day. It indicated that the digestion still occurred in the reactor due to the heat generated normally from organic digestion [21]. Lastly, the digestion of $0.5 \%$ TVS of SS showed the smallest rise because the smaller volume of SS was filled into the system. The results supported that this digestion should not take more than 4 days since the digestion systems approached the constant in all VFA yield, $\mathrm{pH}$ and temperature.

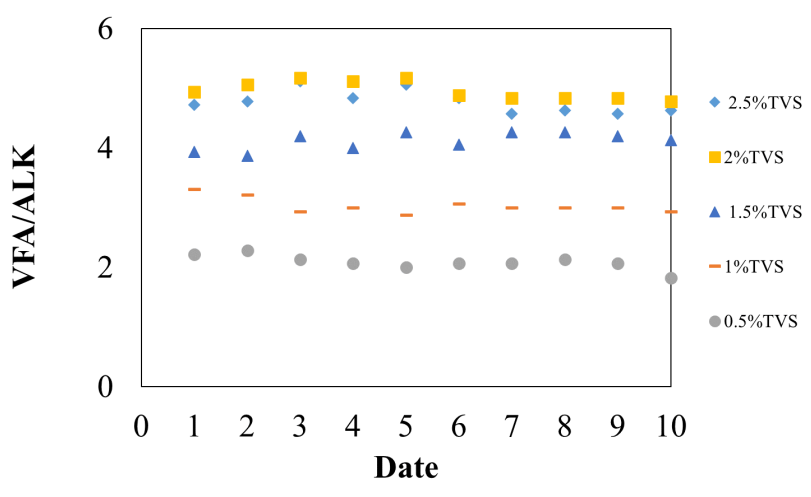

Figure 6 The ratios of VFA/ALK. 


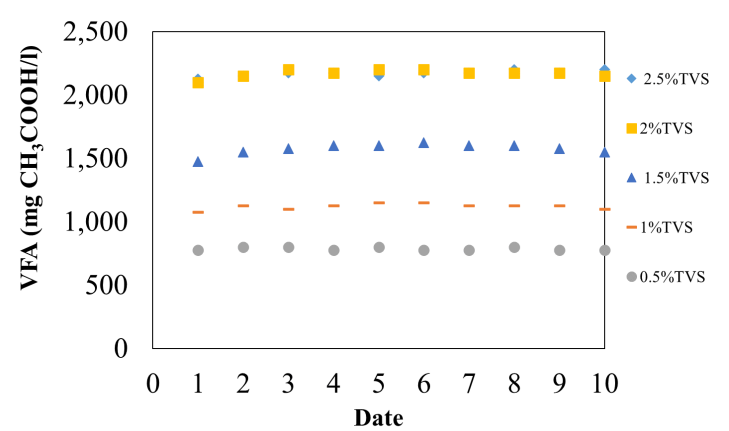

(A)

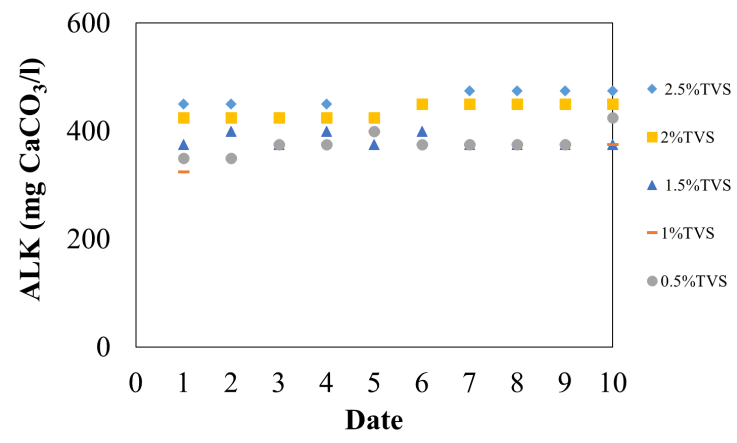

(B)

Figure 7 Represents (A) VFA and (B) ALK values at various initial SS concentrations.

The ratios of VFA/ALK were considered more vital than $\mathrm{pH}$ values to monitor system stability (Figure 6). The increase of VFA/ALK varied directly with the increase of SS concentrations. Markedly, these ratios as $4.8-5.2$ at $2 \%$ of SS were quite close to $4.6-5.1$ at $2.5 \%$ TVS of SS. However, the ratio of the VFA/ALK stayed high compared to other studies. For example, Schievano et al. [22] showed the proper VFA/ALK of $0.95 \pm 0.06$ from the co-digestion of pig manure with market waste in the CSTR at thermophilic condition. Gnanapragasam et al. [23] found that the VFA/ALK of $1.48-1.51$ was appropriate for mesophilic acidogenesis of textile dyeing effluent using a pilot UASB reactor. Lastly, the thermophilic acidogenesis stage of the 2-stage AD of palm oil mill effluent had the proper VFA/ALK ratios between 1.59 - 2.49 [24]. But this work was near the acid production in the leach bed reactor (LBR) of AD of napier grass with the ratio of VFA/ALK at 3.0 [25]. Since the SS substrate consisted of much glucose, it looks like in the napier grass comprising mainly cellulose and hemicellulose that could convert into many glucoses and other sugar monomers [26].

When considering both VFA and ALK values in detail, as shown in Figures 7(A) and 7(B), respectively. It was found that the VFA of both SS concentrations was to get laid on the same value. While at $2.5 \%$ of SS had a slightly higher ALK value than at $2.0 \%$ TVS of SS. As the result of SS consisted of the main content of starch (70-85\% of amylopectin and 15-30\% of amylose) that was digested into glucose [27]. Therefore, ALK buffering in this system came from carbonate $\left(\mathrm{CO}_{3}{ }^{2-}\right)$ and bicarbonate $\left(\mathrm{HCO}_{3}^{-}\right)$ions, which occurred from the digestion of glucose to VFA acetic acid $\left(\mathrm{CH}_{3} \mathrm{COOH}\right)$, butyric acid $\left(\mathrm{CH}_{3} \mathrm{CH}_{2} \mathrm{CH}_{2} \mathrm{COOH}\right)$ and carbon dioxide $\left(\mathrm{CO}_{2}\right)$ (Eqs. (2) and (3)) [28,29]. Subsequently, $\mathrm{CO}_{2}$ reacted with $\mathrm{H}_{2} \mathrm{O}$ converting into $\mathrm{HCO}^{3-}$ (Eq. (4)) and $\mathrm{CO}_{3}{ }^{2-}$ (Eq. (5)) [30]. The $\mathrm{HCO}_{3}{ }^{-}$ion may be the main alkaline factor in this digestion due to the system operated with a $\mathrm{pH}$ lower than 6 [31]. The ALK varied little directly with the change in the SS concentration.

$$
\begin{aligned}
& \mathrm{C}_{6} \mathrm{H}_{12} \mathrm{O}_{6}+2 \mathrm{H}_{2} \mathrm{O} \longrightarrow 2 \mathrm{CH}_{3} \mathrm{COOH}+\mathbf{2} \mathbf{C O}_{2}+4 \mathrm{H}_{2} \\
& \mathrm{C}_{6} \mathrm{H}_{12} \mathrm{O}_{6} \longrightarrow \mathrm{CH}_{3} \mathrm{CH}_{2} \mathrm{CH}_{2} \mathrm{COOH}+\mathbf{2} \mathbf{C O}_{2}+2 \mathrm{H}_{2} \\
& \mathbf{C O}_{2}+\mathrm{H}_{2} \mathrm{O} \longrightarrow \mathrm{H}^{+}+\mathrm{HCO}_{3}{ }^{-} \\
& \mathrm{HCO}_{3}{ }^{-}+\mathrm{OH}^{-} \longrightarrow \mathrm{CO}_{3} \longrightarrow \mathrm{CO}_{3}{ }^{2-}+\mathrm{H}_{2} \mathrm{O}
\end{aligned}
$$

Lastly, the overall results represented that the equative appreciated VFA concentration in 2 and 2.5 $\%$ TVS of SS. Moreover, the VFA yield, system stability, and performance were considered. The $2 \%$ TVS of SS was seen as greater VFA yield and proper stability showing the higher $\mathrm{pH}$ and VFA/ALK ratios. While at $2.5 \%$ TVS of SS obtained the lower VFA yield and lower $\mathrm{pH}$, it would adversely impact VFA production. Thus, the next step at the $2 \%$ TVS of SS was appropriate to select for VFA, and bacterial analysis involved classification and quantitation. 


\section{The VFA composition}

The significantly maximum acetic acid content was detected as $79.4 \%$ by weight in the produced solution of CSTR digester (Table 2). The small rest portions were isovaleric acid and propionic acid, only 11.5 and $9.1 \%$ by weight, respectively. The acetic acid was the main product since in this fermentation operated at $\mathrm{pH} 5$, bacteria could produce acetic acid from glucose. According to the theory, the anaerobic digestive $\mathrm{pH}$ ranges from 5 to 6 generates acetic acid as a major VFA [32]. The study of Patel and Pandya [29] confirmed to this work that acetic acid was formed during the fermentation of glucose if acidic $\mathrm{pH}$ was maintained at around 4.5 at mesophilic condition. At the same time, the ratio of propionic acids and isovaleric acids to acetic acids was evaluated as in dictator for digestion capacity by bacteria. The very lower values for these ratios of 0.11 and 0.15 , respectively (ratios less than 1.4 [25]), indicated that the more effective organic conversion to make up for acetic acids by almost $79.4 \%$ by weight. Some reports in the research literature showed the acetic acids from $\mathrm{AD}$ could be beneficially used as natural contact herbicide for weed control in the organic farm [33]. Also, the use was as an additive to coal-fired combustion units to control sulfur emission [34]. Thus, using the produced acetic acid from this experiment is possible, according to the founding information.

Table 2 The analysis of VFA composition at the optimum initial SS concentration.

\begin{tabular}{cc}
\hline Type of VFA & Percent by Weight \\
\hline Acetic acid & 79.4 \\
Propionic acid & 9.1 \\
Isobutyric acid & - \\
Butyric acid & - \\
Isovaleric acid & 11.5 \\
Valeric acid & - \\
\hline
\end{tabular}

\section{The bacterial diversity}

The bacterial diversity of granular sludge in CSTR at a loading rate of $2 \%$ TVS of SS was selected to identify. An overview of the 5 predominant bacterial genera was depicted in Figure 8. The main bacteria were affiliated to the Arenimonas over $33 \%$. The following predominant bacteria were Longilinea, Desulfovibrio, and Syntrophomonas, equal to 13,11 and $11 \%$, respectively. It is well known that Arenimonas can be found generally in the water resource to produce drinking water [35] which corresponds to the source of inoculum in this research getting from the beverage and drinking water production factory. Moreover, such data pointed out that Arenimonas prefers to grow in solid media containing glucose the sole carbon source [36]. It can grow in the wide $\mathrm{pH}$ range of $5-10$ at mesophilic conditions [35]. In contrast, Longilinea, Desulfovibrio and Syntrophomonas like to use the other organics; protein [37], and VFA [38], respectively. Therefore, the selection of the inoculum for the SS digestion should be based on as bacterial domains tend to favor glucose. Such as Aremimonas was found to be a significant genus.

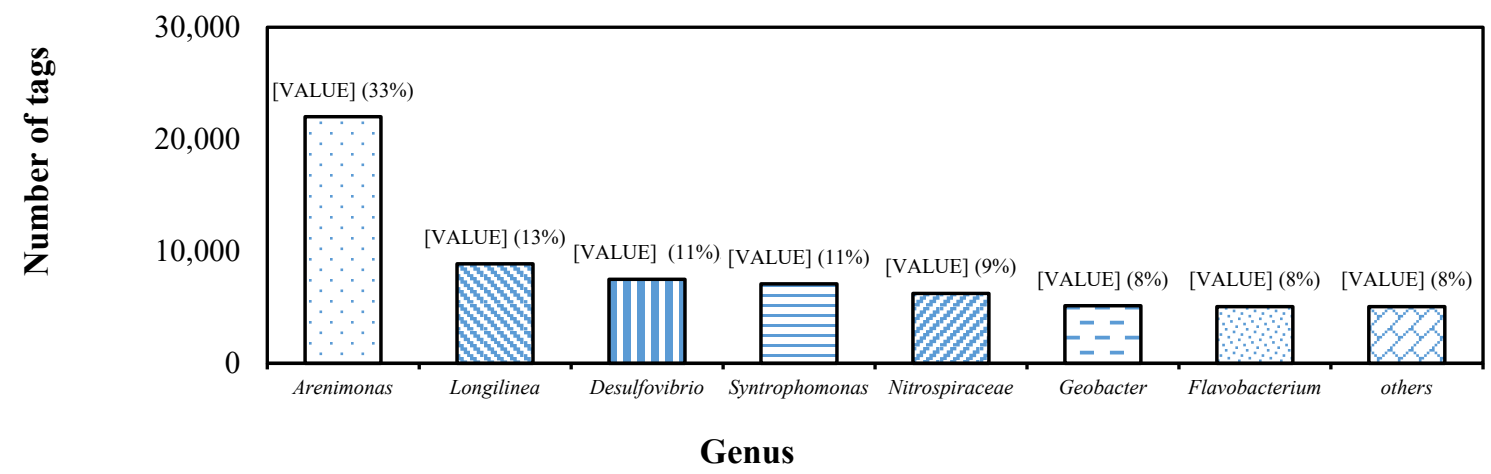

Figure 8 The analysis of bacterial diversity in CSTR at the optimum initial SS concentration. 


\section{Conclusions}

The results indicated that SS waste from the modified tapioca starch plant had sufficient potential for VFA production. But the user must be aware of their overconcentration feeding that may affect the efficiency, system performance and stability. This research suggested that at $2 \%$ TVS of SS could achieve the high VFA yield, including the proper system stability. The higher concentration of SS feeding should be studied further as a suitable way for improvement such as chemical adding, operating adjustment, etc.

\section{Acknowledgments}

The authors would like to special thanks to School of Public Health, University of Phayao, Thailand, for technical and laboratory support. We deeply appreciate Mr. Sirichai Suwanlamai for all your help and support. This research project was supported by The Thailand Science Research and Innovation Fund and University of Phayao (Grant No. FF65-RIM147).

\section{References}

[1] S Achinas, Y Li, V Achinas and GJW Euverink. Biogas potential from the anaerobic digestion of potato peels: Process performance and kinetics evaluation. Energies 2019; 12, 2311.

[2] G Strazzera, F Battista, NH Garcia, N Frison and D Bolzonella. Volatile fatty acids production from food wastes for biorefinery platforms: A review. J. Environ. Manage. 2018; 226, 278-88.

[3] I Baumann and P Westermann. Microbial production of short chain fatty acids from lignocellulosic biomass: Current processes and market. Biomed. Res. Int. 2016; 2016, 8469357.

[4] M Atasoy, I Owusu-Agyeman, E Plaza and Z Cetecioglu. Bio-based volatile fatty acid production and recovery from waste streams: Current status and future challenges. Bioresour. Technol. 2018; 268, 773-86.

[5] Y Li, D He, D Niu and Y Zhao. Acetic acid production from food wastes using yeast and acetic acid bacteria micro-aerobic fermentation. Bioprocess Biosyst. Eng. 2015; 38, 863-9.

[6] M Ehsanipour, AV Suko and R Bura. Fermentation of lignocellulosic sugars to acetic acid by Moorella thermoacetica. J. Ind. Microbiol. Biotechnol. 2016; 43, 807-16

[7] The Thai Tapioca Products Factory Association. The price of tapioca by-product in Thailand, Available at: http://thaitapioca.org/, accessed August 2018.

[8] The Food-Info team of Wageningen University. Starch from Wageningen University, The Netherlands, Available at: http://www.food-info.net/uk/carbs/starch.htm, accessed August 2018.

[9] TG Saeed, M Fereshteh, S Eilya and A Ali. Effect of amylose/amylopectin ratio on physicomechanical properties of rubber compounds filled by starch. J. Appl. Chem. Res. 2010; 4, 53-60.

[10] CE Manyi-Loh, SN Mamphweli, EL Meyer, AI Okoh, G Makaka and M Simon. Microbial anaerobic digestion (bio-digesters) as an approach to the decontamination of animal wastes in pollution control and the generation of renewable energy. Int. J. Environ. Res. Public Health 2013; 10, 4390-417.

[11] A Hussain, M Filiatrault and SR Guiot. Acidogenic digestion of food waste in a thermophilic leach bed reactor: Effect of $\mathrm{pH}$ and leachate recirculation rate on hydrolysis and volatile fatty acid production. Bioresour. Technol. 2017; 245, 1-9.

[12] M Hutnan, M Drtil, J Derco, L Mrafkova, M Hornak and S Mico. Two-step pilot-scale anaerobic treatment of sugar beet pulp. Pol. J. Environ. Stud. 2001; 10, 237-43.

[13] J Yi, B Dong, J Jin and X Dai. Effect of increasing total solids contents on anaerobic digestion of food waste under mesophilic conditions: Performance and microbial characteristics analysis. PLoS One 2014; 9, e102548.

[14] Y Choi, J Ryu and SR Lee. Influence of carbon type and carbon to nitrogen ratio on the biochemical methane potential, pH, and ammonia nitrogen in anaerobic digestion. J. Anim. Sci. Technol. 2020; 62, 74-83.

[15] B Fu, J Zhang, J Fan, J Wang and H Liu. Control of $\mathrm{C} / \mathrm{N}$ ratio for butyric acid production from textile wastewater sludge by anaerobic digestion. Water Sci. Technol. 2012; 65, 883-9.

[16] Lukitawesa, RJ Patinvoh, R Millati, I Sarvari-Horvath and MJ Taherzadeh. Factors influencing volatile fatty acids production from food wastes via anaerobic digestion. Bioengineered 2020; 11, $39-52$. 
[17] SY Xu, OP Karthikeyan, A Selvam and JWC Wong. Effect of inoculum to substrate ratio on the hydrolysis and acidification of food waste in leach bed reactor. Bioresour. Technol. 2012; 126, 42530 .

[18] RB Baird and AD Eaton. Standard methods for the examination of water and wastewater. 23 eds. American Public Health Association, Washington DC, 2017.

[19] M Gruhn, JC Frigon and SR Guiot. Acidogenic fermentation of Scenedesmus sp.-AMDD: Comparison of volatile fatty acids yields between mesophilic and thermophilic conditions. Bioresour. Technol. 2016; 200, 624-30.

[20] JM Lema and S Suarez. Innovative wastewater treatment \& resource recovery technologies: Impacts on energy, economy and environment. IWA Publishing, London, 2017.

[21] H He, X Ji, X Xie, X Ding, F Wang, J Ding and R Tang. Energy and economic evaluation of three generations of anaerobic reactors for starch wastewater treatment. Environ. Pollut. Bioavail. 2019; 31, 252-60.

[22] A Schievano, A Tenca, B Scaglia, G Merlino, A Rizzi, D Daffonchio, R Oberti and F Adani. Twostage vs single-stage thermophilic anaerobic digestion: Comparison of energy production and biodegradation efficiencies. Environ. Sci. Technol. 2012; 46, 8502-10.

[23] G Gnanapragasam, V Arutchelvan and L Soundari. Effect of temperature on biodegradation of textile dyeing effluent using pilot scale UASB Reactor. Int. J. Environ. Agric. Res. 2016; 2, 158-62.

[24] B Trisakti, Irvan, H Adipasah, I Zahara, Taslim and M Turmuzi. Effect of agitation on acidogenesis stage of two-stage anaerobic digestion of palm oil mill effluent (POME) into biogas. In: Proceedings of the IOP Conference Series: Materials Science and Engineering, Bali, Indonesia. 2017, p. 1-8.

[25] A Thaemngoen, K Saritpongteeraka, SY Leu, C Phuttaro, C Sawatdeenarunat and S Chaiprapat. Anaerobic digestion of napier grass (Pennisetum purpureum) in two-phase dry digestion system versus wet digestion system. Bioenergy Res. 2020; 13, 853-65.

[26] L Zhang, KC Loh and J Zhang. Food waste enhanced anaerobic digestion of biologically pretreated yard waste: Analysis of cellulose crystallinity and microbial communities. Waste Manage. 2018; 79, 109-19.

[27] AL Adejumo, FA Aderibigbe and RU Owolabi. Relationship between $\alpha$-amylase degradation and amylose/amylopectin content of maize starches. Adv. Appl. Sci. Res. 2013; 4, 315-9.

[28] R Moreno, EJ Martinez, A Escapa, O Martinez, R Diez-Antolinez and X Gomez. Mitigation of volatile fatty acid build-up by the use of soft carbon felt electrodes: Evaluation of anaerobic digestion in acidic conditions. Fermentation 2018, 4, 2.

[29] R Patel and HN Pandya. Production of acetic acid from molasses by fermentation process. Int. J. Adv. Res. Innov. Ideas Educ. 2015; 1, 58-60.

[30] HHP Fang and T Zhang. Anaerobic biotechnology: Environmental protection and resource recovery. Imperial College Press, London, 2015.

[31] K Martyn. Buffers for duffers, Available at: https://microscopesandmonsters.wordpress.com/2017 /10/14/buffers-for-duffers, accessed August 2017.

[32] E Kebreab, J Dijkstra, A Bannink and J France. Recent advances in modeling nutrient utilization in ruminants. J. Anim. Sci. 2009; 87, E111-E122.

[33] CL Webber, PMJ White, JW Shrefler and DJ Spaunhorst. Impact of acetic acid concentration, application volume, and adjuvants on weed control efficacy. J. Agric. Sci. 2018; 10, 1-6.

[34] ST Yang, Z Jin and BH Chollar. Production of low-cost acetate deicers from biomass and industrial wastes. Transportation Research Board, National Research Council, Washington DC, 1997, p. 60-9.

[35] J Makk, ZG Homonnay, Z Keki, K Nemes-Barnas, K Marialigeti, P Schumann and EM Toth. Arenimonas subflava sp. nov., isolated from a drinking water network, and emended description of the genus Arenimonas. Int. J. Syst. Evol. Microbiol. 2015; 65, 1915-21.

[36] NVP Majeti. Bioremediation and bioeconomy. Elsevier, Boston, 2015.

[37] T Yamada, H Imachi, A Ohashi, H Harada, S Hanada, Y Kamagata and Y Sekiguchi. Bellilinea caldifistulae gen. nov., sp. nov. and Longilinea arvoryzae gen. nov., sp. nov., strictly anaerobic, filamentous bacteria of the phylum Chloroflexi isolated from methanogenic propionate-degrading consortia. Int. J. Syst. Evol. Microbiol. 2007; 57, 2299-306.

[38] J Li, Q Ban, L Zhang and AK Jha. Syntrophic propionate degradation in anaerobic digestion: A review. Int. J. Agric. Biol. 2012; 14, 843-50. 